\title{
The Future of the University
}

\author{
J ÜR GEN MITTELSTRASS \\ Center for Philosophy of Science, University of Constance, Germany. E-mail: \\ Juergen.Mittelstrass@uni-konstanz.de
}

I am not a prophet, nor can I look into the future - not even at the end of this productive conference on essential changes in the higher education system. When the work situation of the academic profession, its diversification and academic freedom are at issue, the university as a whole is called into question, at least the university as we have known and appreciated it for a long time. Will that university have a future? This is not clear at all, especially when we consider the managerial university and the ever increasing marketisation of all aspects of university life. In the following, I present a few remarks about the continuously fading theory of the university, centred on the keywords education, university, universality, and quality.

\section{Education}

The university is changing because its social and institutional environment is changing, and because science itself is changing. This development is often shaped by political and economical constraints, external factors forcing internal reorganisation. Wherever scientific reason prevails in this situation and these external constraints are faced with institutional imagination, things work out fine. Wherever it remains idle and political and economic constraints take the upper hand, the university is threatened with the loss of its essential nature, which consists of an autonomous organisation for research and teaching, together with, and joined by, a concept of education that both reflects and gives a critical selfconsciousness to the modern world, which is essentially scientific in nature.

In this world, the pressure to change constantly and to specialise our knowhow is steadily increasing. This drive towards specialisation stands in peculiar contrast to the simultaneous 'technological' integration of knowledge. This integration, which is effected by modern information and communication technologies, does not, however, lead to a new (or old) unity of the universally 
oriented (and thus universally orienting) polymath, but rather to the creation of the expert. The modern world is a world of experts: it is not ruled by a Leibnizian understanding (i.e. one that mirrors the world), but by the specialist, who reflects nothing or - to paraphrase the German poet Friedrich Schiller - a divided world at best. The specialist, who knows more and more about less and less, has landed on the other side of universality: he seeks it in details, which to him mean totality.

But this will hardly do. In a world of experts, the old ideal of unified knowledge, even if the latter is still to be pursued 'technologically', loses its social function. The distinction between 'universal' and 'disciplinary' knowledge, i.e. between the responsibility for the whole and the part, begins to fade, and this is true most of all when the knowledge society begins to see itself as an information society. That is why the present reincarnation of the knowledge society as an information society threatens to disappointment us, at least to the degree that these terms denote an informed rather than an oriented society. How such an oriented knowledge can be achieved - and by this I mean knowledge that is not to be confused with mere expert knowledge - is thus not a question that can be answered by an appeal to yet more information. It is actually a paradox: the richer our stores of information and knowledge, the poorer our ability to orient ourselves. But this ability is precisely what education once stood for.

Education is the expression of a culture in which the rational nature of Man is realised, and simultaneously, it us the obverse of culture (which has become an individual form of life). Wilhelm von Humboldt is still in the right. For him, an educated person is someone who tries 'to grasp as much of the world as is possible, and who tries to bind it to him as tightly as possible'. ${ }^{1}$ The locus of orientation is the life-world, not the conceptual or theoretical world. And this holds true of education as well. Education and orientation are structurally correlated, not so much in the form of science as in the form of life; that is to say, in the form of an ability. Following Humboldt, we might say that it is the ability to integrate the world in oneself and to express the world in itself: knowledge is the universal expressed as a particular, at least if one considers knowledge and experience and deals with them sensibly.

What I have just formulated in rarefied and abstract - i.e. in what is commonly called educated - language, in my opinion describes quite exactly the sense in which a humanist educational ideal might be reintroduced into our culture, and also our university culture. It is concerned with an active conceptualisation of the world, and is opposed to an essentially economic preference of the Zeitgeist for a divided self; that is to say, a self split into a private, a social and a consumer self. As such, the conceptualisation is concerned with the restoration of an undivided self, and with restoring clarity to the concept of knowledge by means of which our society defines itself. And this is also something the university, caught in the Bologna process and lured into managerial and economic ideologies, has to learn again. 


\section{University}

Every institution, every system that takes its fate into its own hands and does not just think in terms of external dependencies, must think in terms of a planned development, starting from an assessment of its current situation and the course it wants to follow. Keeping in mind the observations on education made above, this particularly applies to universities. The modern keywords are profile-building and new university structures.

Of course, a university is a type of institution where not everything can be planned for, because the same holds true for science, the institutional heart of the university. From this it is often inferred that planning is antagonistic to science and universities, and that it attempts to obstruct or revoke the essence of academic freedom, the freedom of research and teaching - in other words, that planning is part of the vocabulary of constraints. But this belief is erroneous. Science, research and teaching should not situate themselves beyond the reach of clear ideas of aspired and desired developments. Otherwise, they would put their trust in natural development, rather than in a rationally justified or justifiable development.

Therefore, it is important to awaken an institutional consciousness in the universities that does not think in, and so protects, categories of what already exists (i.e. for individual utility), but in the categories of a development in which the tried and tested concepts of old are combined with the desirable new in order to form functional structures of organisation that foster such a thinking. It will be essential to practice autonomy not just towards the external, as political autonomy, but also internally, as structural autonomy. Structural autonomy shows itself primarily in the realisation of structures informed by thinking about the systematic nature of science, e.g. at the level of the organisation of subjects and disciplines, the establishment and abolition of degrees and areas of specialisation in research, but also in the implementation of quality standards following international standards in research, teaching, and the education of junior academic staff. Where this is not feasible or not desired, autonomy, in the form of an isolating strategy with respect to interference of any sort, will lead to structural immobility and ultimately to the university bidding farewell to general development. For example, we all know that science and research are increasingly becoming trans-disciplinary, reaching beyond individual subjects and the core areas of single disciplines, and the institutional structure has to take this into account. This means that a system of science - the one that is given or can be realised at any university - has to follow the developments of research and science and has to create the adequate institutional background for this - in any case, the development of research or science should not be stifled by simply adhering to the existing system. Many universities still have to learn that. To become a managerial 
university (or to introduce any system as a result of university politics without due reflection) is of secondary importance.

One thing seems sure. The present situation replicates that of the late Middle Ages, when, for example, Oxford, Paris, and Padua were competing with each other, and not, locally, Oxford with Glasgow, Paris with Avignon, and Padua with Ferrara. While this competition did exist, mostly in individual disciplines, science and education as a whole was defined on the European level. As far as top research and education are concerned, in the foreseeable future between 20 to 30 universities will come to define the top level in Europe. Therefore, every university and national higher education policy should now be concerned with what its future role might or should be. Whoever fails to take the necessary steps now will miss the boat, provided that there is a willingness to move into this direction at all.

In any case, certainly not all universities will be in the position to do this. Just as one cannot simply decide to become a research university, let alone an elite university, from one day to the next, even when sufficient funding is available, one cannot simply decide to play in the same league with the best European universities in the foreseeable future. A certain size and the corresponding variety of disciplines and levels of achievement in combination with as a strong scientific environment yielding desirable synergies are just some of the institutional preconditions required for this. This does not entail, in turn, that universities that do not dispose of such an environment do not have a future. After all, universities are not simply founded for scientific reasons, but equally, if not primarily, for more general reasons of higher education and regional politics. In this respect, they meet a specific need, i.e. the need for higher education, which often is not so much defined in terms of any scientific need as in terms of the needs of a particular state or region. Although this does not lower the scientific requirements, formulated on the principle of the unity of teaching and research in the Humboldtian university, it does not put universities under pressure to be or become something which, under the given circumstances, is out of reach for them.

But even in such a case, one thing is clear: every university is well-advised to create its own profile and to build up its strengths accordingly. It has to show what it stands for in science and higher education, and what it may or may not accomplish with the means at its disposal. This will almost inevitably lead to a differentiated university system in which there will be academic inequality, because there will be unequally distributed universality (as far as the variety of subjects and disciplines are concerned) and varying degrees of scientific quality and excellence. It is an illusion to believe that with regard to scientific quality any university system may continue to be run as an essentially homogeneous system - as once many (often significantly smaller) institutions were run. In the long run, keeping homogeneity as the measure of all university affairs will inevitably lead to rampant mediocrity. 


\section{Universality and other virtues}

A university meeting the requirements mentioned above must either answer or be able to demonstrate its institutional response to the following questions: what level of universality does a university need to attain before it can live up to its name? How much plurality does a university need to establish a specific identity? How much quality is needed before excellence can emerge?

The first question is what level of universality a university needs to attain before it really becomes a university. Despite all tendencies toward specialisation, academic knowledge is something that only thrives on a field kept by all involved parties. Great achievement requires not only specialised knowledge, but also close contact to other areas. Robert Boyle was a physicist and chemist, Gottlob Frege a mathematician and philosopher, Max Weber was a sociologist and historian, Max Delbrück a biologist and physicist. In their cases, disciplinary boundaries did not determine their actual achievements - on the contrary, these boundaries had to be overcome before great achievements could be attained. This is also and especially true for modern developments. New insights most often form on the edges of fields and disciplines, and not at the core, where textbook knowledge is at home. Thus, universality, in its institutional forms of fields and disciplines, cannot be restricted arbitrarily: in departmental or disciplinary greenhouses, research and teaching can only thrive to a certain degree. Access to environments external to that of the university must remain open, and open in both directions: one must be able to get outside when one is looking for complementary knowledge, and others with the same desire must be able to get in. This means that the university must hold to its claim to universality.

Second, how much plurality does a university need to establish a specific identity? Disciplinary plurality bestows upon the university a sense of self, the sense of being a real university. If this plurality is not present, this sense of being a university will not develop, and universities will remain mere schools. In such cases, the unity of research and teaching still defines itself by what a circumscribed part of academia knows, but this means that it is defined by a closed form of research, and not the open one that is one of the characteristics of today's inter- or trans-disciplinary perspective. The paradigm of the school replaces that of the university. The university as an institution of teaching displaces the university as a research institution; the unity of research and teaching loses its content and coagulates in rhetoric.

Third, how much quality is needed before excellence can emerge? Universities are institutions of higher learning in the sense that university teaching develops out of university research, and thus remains connected to the latter through teaching and learning. If teaching and learning are disconnected from research, or remain connected to the latter only by the memory of the teacher's own learning, such terms as 'academic' and 'scientific', or the German 'wissenschaftlich' lose their meaning. In this case, university teaching and learning are no longer distinguished from other, 
non-academic, teaching and learning. Academic achievement of a high calibre and scientific excellence are once again only possible in an environment that is conducive to achievement, which stimulates and furthers academic achievement through academic achievement itself. Although mediocre conditions do not necessarily exclude a high level of achievement, or occasional feats of excellence, this will remain the exception. In general, mediocre conditions are a programme for academic mediocrity, true to André Weil's law of university hiring: first-rate people hire other first-rate people, but second-rate people hire third-rate people. A university needs a lot of academic quality if academic excellence is to be developed. And this quality cannot be found in isolated fields or on disciplinary islands, but should be pursued in an academic and scientific context defined by quality and excellence. Differentiation and diversification are the engine that drives the development of the university, and thus, of higher education.

\section{Quality and the researcher}

The final question that has to be answered is how individuals involved in teaching and research do in view of the fact that the institutions at which they work increasingly have to meet economic and regulatory demands. In the following discussion, I shall use quality assessment and the organisational structure of research as examples.

In the 1960 s and $1970 \mathrm{~s}$, universities had to cope with the fact that all university relations had to be assessed first in sociological terms and then in didactic terms. The present credo is that of evaluation: 'I am evaluated, therefore I am' could be the motto of today's higher education institutions, and this perspective is rapidly becoming omnipresent at all institutional levels. ${ }^{2}$

Quality assessment procedures for higher education institutions in Europe were first developed in the mid-1980s. Most European countries have systems of quality assessment or quality assurance at their disposal. This development has been spurred by the desire to give more autonomy to higher education institutions and to ask for efficient accountability. This is a noble aim, but the methods chosen to attain it are wrong. The danger is that by attempting to subject the academic practice to standardised criteria, it may lose its essential capacity. In the case of science, this essence is in the discovery of what is new. This may come in many ways, well-known and new. Therefore, optimal methods are not easy to lay down from the start and cannot be restricted by rules to be followed and controlled, for example in terms of quality. This is related to the fact that in science - as in many other social areas - people are the essential factor, not the routines they follow (in which people are viewed as interchangeable commodities). It is the researcher who is at the centre of successful research, not the research system, be it assessed or not. 
Moreover, quality cannot be defined independently of given circumstances aims, goals, methods, subjects. There is no general definition of quality, and no model that could stand for all areas in which quality is at stake. This applies also to research and teaching, which is why quality assessment in (institutions of) higher education is still, in a way, an art without a master. This again means that, on the one hand, quality assessment is a (mostly imperfect) tool supposed to solve problems of academic self-perception, and, on the other, a problem in itself. The fact that there exists a constantly growing industry of assessment and evaluation should not deceive us. Where everybody assesses everybody else - and we are moving in this direction - the blade of criticism becomes blunt; what in former times used to serve well-defined aims of optimising research and teaching becomes an end in itself. We know this from science policy studies, namely from (empirical) research about the way in which, and under what institutional conditions, research is carried out. But this does not make research better - rather, it considers it as an object that can be examined like any other object.

This particularly applies to research. A peculiar terminology is spreading. When today we refer to research, we primarily mean research groups, temporary grant-funded research centres, clusters, and alliances. Research appears, first of all, as something that needs to be organised, not as something that is the project of the person actually doing the research. The concept of research itself is changing. While it used to be closely connected to the researcher, this connection is starting to dissolve. The search for truth, which used to be part of the selfconception of the scientist and was what turned him or her into a researcher to begin with, becomes research as an organisation, i.e. a process to be organised, behind which the scientist is disappearing. ${ }^{3}$ The individual scholar engaged in research becomes 'research'; that is to say, he or she becomes institutionalised and de-individualised in specialised research institutions. Owing to their teaching requirements, universities are ever less in a position to present themselves as such. Instead, research becomes the 'business' of institutions specifically founded for this purpose, especially in the areas of natural science and technology. Research as an individual form of life thus turns into research as business, organised in teams, one-off research projects, and research alliances. We are driving the individual out of research - and out of teaching, too, to the extent that with the Bologna process the standardisation of teaching will increase, turning the university more and more into a school - the teacher is disappearing behind organised processes.

\section{Final remark}

We cannot foresee the future of the university. But what we discover does not bode well, at least not for those of us who still believe in the ideal of the 
university or do not conceive of research as just another job. The university, which nowadays is talked about in a strange administrative and economic language, no longer corresponds to any theory or idea, and the conviction that science in teaching and research is not just another job, but a way of life, is being exorcised from those working in it. We need to beware of letting the university system erode in this manner. Such a system would lose research to extra-university institutions once and for all, and universities would evolve into mere teaching institutions. That too could be one of the messages of our conference.

\section{Acknowledgement}

The author acknowledges the support of the Fondazione Compagnia di San Paolo.

\section{References}

1. W. v. Humboldt (1793/1903) Theorie der Bildung des Menschen (Bruchstück). In: Gesammelte Schriften, vol. 1 of 17 (Berlin: B. Behr), pp. 255.

2. J. Mittelstraß (2007) Quality assessment in higher education institutions from the perspective of those assessed. International Journal for Education Law and Policy, 3(3), 37-40.

3. H. Plessner (1966) Zur Soziologie der modernen Forschung und ihrer Organisation in der deutschen Universität: Tradition und Ideologie. In: Diesseits der Utopie: Ausgewählte Beiträge zur Kultursoziologie (Düsseldorf and Cologne: Eugen Diederichs Verlag), pp. 121-142; H. Schnaedelbach (1991) Philosophie in Deutschland 1831-1933, 4th edn (Frankfurt: Suhrkamp), pp. 41f.

\section{Further Reading}

P. G. Altbach (ed.) (2000) The Changing Academic Workplace: Comparative Perspectives (Boston: Boston College).

R. Barnett and R. Middlehurst (1993) The lost profession. Higher Education in Europe, 2, pp. 110-128.

B. R. Clark (1977) Academic Power in Italy: Bureaucracy and Oligarchy in a National University System (Chicago: University of Chicago Press).

J. Enders (ed.) (2000) Academic Staff in Europe: Changing Contexts and Conditions (Westport: Greenwood).

J. Enders (2006) The academic profession. In: International Handbook of Higher Education, vol. 1, edited by J. F. Forest and P. G. Altbach (eds) (Dordrecht: Springer), pp. 5-22.

J. Enders and E. de Weert (2004) The International Attractiveness of the Academic Workplace in Europe (Frankfurt/Main: GEW).

J. Enders and C. Musselin (2008) Back to the future? The academic professions in the 21st century. In: Higher Education to 2030, vol. 1: Demography (Paris: UNESCO).

A. H. Halsey (1992) Decline of Donnish Dominion: The British Academic Profession in the Twentieth Century (Oxford: Clarendon Press). 
M. Henkel (2005) Academic identity and autonomy in a changing policy environment. Higher Education, 49(1\&2), 155-176.

M. Kogan, I. Moses and E. El-Khawas (eds) (1994) Staffing Higher Education: Meeting New Challenges (London: Jessica Kingsley Publishers).

M. Kogan and U. Teichler (eds) (2007) Key Challenges to the Academic Profession (Kassel and Paris: INCHER-Kassel and UNESCO Forum on Higher Education, Research and Innovation).

W. Locke and U. Teichler (eds) (2007) The Changing Conditions for Academic Work and Careers in Select Countries (Kassel: INCHER-Kassel).

P. M. Maassen and F. A. van Vught (eds) (1996) Inside Academia: New Challenges for the Academic Profession (Utrecht: De Tijdstroom).

R. K. Merton (1976) Sociological Ambivalence and Other Essays (New York: The Free Press).

G. Neave and G. Rhoades (1987) The academic estate in Western Europe. In:

The Academic Profession, edited by B. R. Clark (Berkeley: University of California Press), pp. 211-270.

\section{About the Author}

Jürgen Mittelstraß earned his $\mathrm{PhD}$ in philosophy in 1961 from the University of Erlangen, and his Habilitation in 1968. From 1970 to 2005 he was professor of Philosophy and Philosophy of Science at the University of Constance, and since 1990 also Director of the Center for Philosophy of Science. He was a member of the German Science Council (1985-1990), of the Senate of the German Research Society (1992-1997) and of the German Chancellor's Council for Research, Technology, and Innovation (1995-1998); since 2003 he has been a member (since 2005 Chairman) of the Austrian Science Council. Between 1997 and 1999 he was President of the German Philosophical Association. Currently, he is a member of the Berlin-Brandenburg Academy of Science (Berlin), of the German Academy of Scientists Leopoldina (Halle), of the Academia Europaea (London, 1994-2000 Vice-President, 2002-2008 President) and of the Pontifical Academy of Sciences (Pontificia Academia Scientiarum) (Rome). He was awarded the Leibniz-Prize of the German Research Society in 1989 and the Lorenz Oken Medal of the Society of German Scientists and Physicians in 1998. His numerous publications include: Die Rettung der Phänomene (1962), Neuzeit und Aufklärung (1970), Die Möglichkeit von Wissenschaft (1974), Wissenschaft als Lebensform (1982), Der Flug der Eule (1989), Geist, Gehirn, Verhalten (with M. Carrier, 1989; in English Mind, Brain, Behavior, 1991), Leonardo-Welt (1992), Die unzeitgemäße Universität (1994), Die Häuser des Wissens (1998), and Wissen und Grenzen (2001). He is the editor of Enzyklopädie Philosophie und Wissenschaftstheorie (4 vols. 1980-1996; 2nd edn 2005ff.). 